\title{
Rio Political Declaration on Social Determinants of Health: A Snapshot of Canadian Actions 2015
}

\author{
A. Stankiewicz, MPH; M. Herel, MA; M. DesMeules, MSc
}

Tweet this article

In 2012, Canada and other United Nations (UN) Member States endorsed the "Rio Political Declaration on Social Determinants of Health" (Rio Declaration), ${ }^{1}$ a non-binding pledge which calls on World Health Organization (WHO) Member States to improve/ influence the working and living conditions that affect health and well-being. The Rio Declaration sets out actions to address health inequities in five themes: to adopt better governance for health and development; to promote participation in policy making and implementation; to further reorient the health sector towards reducing health inequities; to strengthen global governance and collaboration; and to monitor and increase accountability.

\section{Canada's commitment to the Rio Declaration}

In 2013, following the endorsement of the Rio Declaration, the Government of Canada released a report to begin to document Canadian actions related to its five themes. ${ }^{2}$ Building on this first report, and in anticipation of WHO reporting on Member State implementation of the Rio Declaration at the May 2015 World Health Assembly, the Government of Canada developed the report, Rio Political Declaration on Social Determinants of Health: A Snapshot of Canadian Actions 2015, ${ }^{3}$ which showcases Canada's recent actions since 2013 contributing to the advancement of the five Rio Declaration themes. The report provides a current picture of the diverse spectrum of activities undertaken across levels of government and sectors to advance health equity and address social determinants of health in Canada, and intends to stimulate global and domestic exchange and uptake of promising practices to advance health equity.

\section{Selection criteria for health equity initiatives and tools}

Key Canadian developments across different levels of government and with civil society include further reorientation of the health sector towards reducing health inequities and initiatives to monitor progress and increase accountability. In all, 29 recent, diverse and multiple Canadian initiatives or tools demonstrating action across the Rio Declaration themes were profiled in the report. ${ }^{3}$ The following selection criteria were developed and used to select the initiatives and tools:

- aligns with at least one or more of the five themes of the Rio Declaration

- was published in 2013 or after

- profiles Canadian action/showcases Canada's value added:

○ national, provincial/territorial and/or federal/provincial/territorial collaborative efforts

$\circ$ public, non-government organizations or private sector efforts

o intersectoral partnership efforts

- may profile a compilation of Canadian experiences from different jurisdictions, including local level
- profiles proven, promising or innovative action (ideally, the initiative or tool should demonstrate the evidence base of evaluation results/its impact)

- profiles action and not position statements/recommended actions

- underwent an appropriate review, for example, a peer-review process, approval process or is informed by evaluation data

- is publicly accessible, i.e. posted on the internet (preferable)

Efforts were also made to profile a balance of upstream and downstream interventions improving health and advancing health equity; profile Aboriginal populations (First Nations, Métis, Inuit); apply a common definition of health equity*; and reflect Canada's commitment to gender equity.

\section{Canadian health equity initiatives and tools}

The highlights of each initiative or tool are summarized in the report, and source websites are provided. The initiatives profiled in Canada's 2015 report demonstrate actions to advance health equity and fall under the following groupings:

- To adopt better governance for health and development:

○ Applying health impact assessment

○ Working across sectors to reduce poverty, improve social protection, advance key determinants, such as housing

*Unless in the context of monitoring, where the term 'health inequalities' is applied.

Author reference:

Social Determinants and Science Integration Directorate, Public Health Agency of Canada, Ottawa, Ontario, Canada

Correspondence: Agata Stankiewicz, Public Health Agency of Canada, 785 Carling Ave., Ottawa, ON K1A 0K9; Tel: 613-410-4130; Email: agata.stankiewicz@phac-aspc.gc.ca 
- To promote participation in policymaking and implementation:

○ Reforming government processes to increase openness of data, transparency and participation, and engaging citizens

- Providing approaches to engage and empower Aboriginal peoples for selfgovernance

- To further reorient the health sector towards reducing health inequities:

○ Integrating equity, including genderrelated considerations, into the design and delivery of programs and services

o Providing capacity and tools to advance health equity

- To strengthen global governance and collaboration:

- Providing financial contribution to countries and international organizations

o Fostering North-South support in information sharing and technical expertise

- To monitor progress and increase accountability:

o Strengthening monitoring systems and methods to report on health inequalities

o Sharing evidence to inform policy and action

These initiatives can be of interest to provincial/territorial, regional and local authorities, as well as national governments and non-government organizations, academic organizations, and professional and civil society organizations working to advance the social determinants of health in Canada and internationally.

Canada will continue to explore opportunities to further advance the social determinants of health and health equity including the implementation of the 2014 resolution endorsed by Canada and other UN Member States: "Contributing to social and economic development: sustainable actions across sectors to improve health and health equity." 4 The resolution calls on Member States to take action on improvements in health and reduction of health inequity across various sectors and levels of government. It builds on and aligns with the Rio Declaration which calls for action across sectors for health and health equity.

\section{References}

1. World Health Organization. Rio Political Declaration on Social Determinants of Health [Internet]. Geneva (CH): World Health Organization; 2011 [cited 2015 Jul 3]. Available from: http://www.who. int/sdhconference/declaration/en/

2. Public Health Agency of Canada. Rio Political Declaration on Social Determinants of Health: A Selection of Canadian Actions 2013 [Internet]. Ottawa (ON): Public Health Agency of Canada; 2013 [cited 2015 Jul 3]. Available from: http://publications.gc.ca/ site/eng/444978/publication.html

3. Public Health Agency of Canada. Rio Political Declaration on Social Determinants of Health: A Snapshot of Canadian Actions 2015 [Internet]. Ottawa (ON): Public Health Agency of Canada; 2015. Available from: http://healthycanadians.gc.ca/publications/ science-research-sciences-recherches/rio/ index-eng.php

4. Contributing to social and economic development: sustainable action across sectors to improve health and health equity (followup of the 8th Global Conference on Health Promotion). World Health Assembly, 67 [Internet]. 2014 [accessed 2015 July 3]. Available from: http://apps.who.int/gb/ ebwha/pdf_files/EB134/B134_R8-en.pdf 